3. Gamillscheg A, Zobel G, Urlesberger B, Berger J, Dacar D, Stein JI, et al. Inhaled nitric oxide in patients with critical pulmonary perfusion after Fontan-type procedures and bidirectional Glenn anastomosis. J Thorac Cardiovasc Surg. 1997;113:435-42.

4. Yahagi N, Kumon K, Tanigami H, Watanabe Y, Haruna M, Hayashi H, et al. Cardiac surgery and inhaled nitric oxide: indication and follow-up (2-4 years). Artif Organs. 1998;22:886-91.
5. Bradley SM, Simsic JM, Mulvihill DM. Hypoventilation improves oxygenation after bidirectional superior cavopulmonary connection. J Thorac Cardiovasc Surg. 2003;126:1033-39.

6. Hoskote A, Li J, Hickey C, Erickson S, vanArsdell G, Stephens D, et al. The effects of carbon dioxide on oxygenation, systemic, cerebral and pulmonary vascular hemodynamics after the bidirectional superior cavopulmonary anastomosis. J Am Coll Cardiol. In press.

\title{
Bonanno's catheter: A less invasive and cost- effective alternative for drainage of pleural effusion
}

\section{Govind K. Chetty, FRCS, Maqsood M. Elahi, MRCS, Vishwanath Siddagangaiah, MBBS, and Joseph N. Leverment, FRCS, Leicester, United Kingdom}

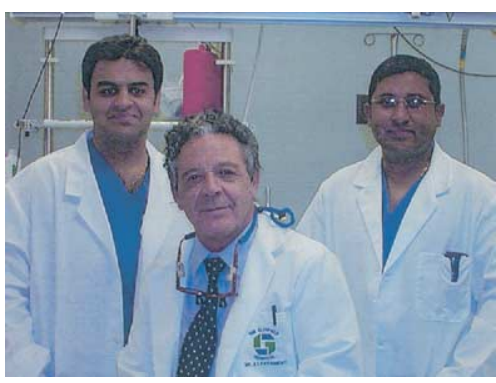

Elahi, Leverment, Chetty (left to right)

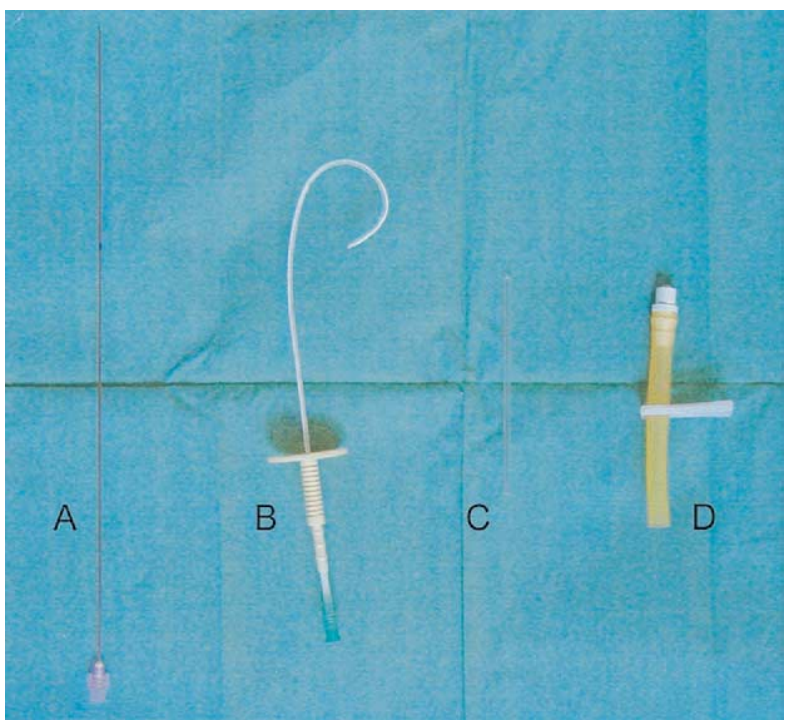

Figure 1. Bonanno's catheter and syringe.

(Figure 1). A 3- to 4-mm incision is made in the skin to avoid damage to the catheter tip, and the catheter is inserted gradually while applying constant suction on the syringe. As soon as serous fluid is aspirated, the trocar is held in a static position while advancing the cannula into the pleural cavity. The trocar is removed, and serous fluid should flow freely from the catheter, which can now be attached with the rubber tubing to a conventional underwater drainage system. The catheter is sutured to the skin, and a chest radiograph will confirm the position of the catheter (Figures 2 and 3).

\section{Conclusion}

Apart from standard tube thoracostomy, which can be quite invasive and painful, ${ }^{2}$ patients with pleural effusion could also undergo 


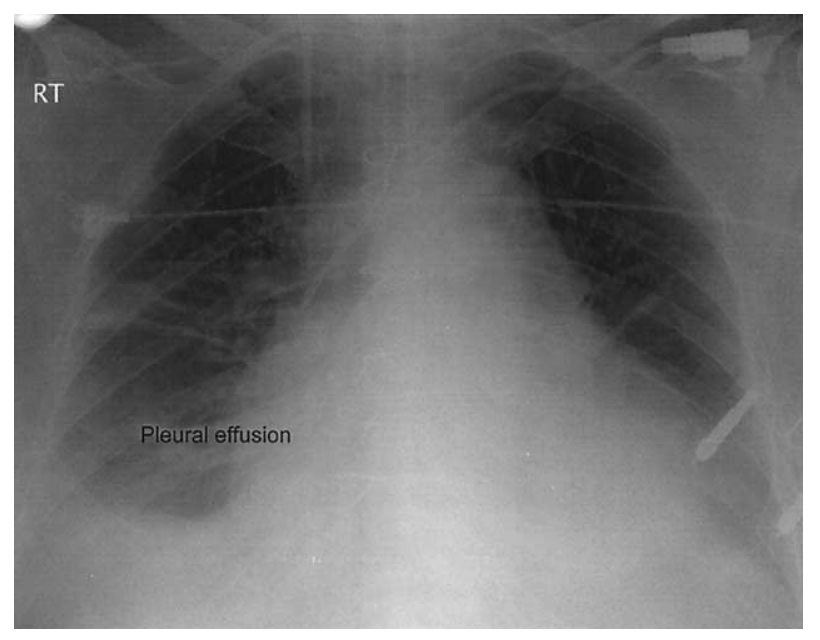

Figure 2. Chest x-ray film showing position.

ultrasound-guided pigtail catheter insertion. ${ }^{3}$ However, the approximate cost associated with insertion of a pigtail catheter under ultrasound control is approximately $£ 106.75$, whereas the cost of Bonanno's catheter is $£ 25.74$. Pleurocentesis can be achieved with needle aspiration; however, this method does not permit complete drainage and is associated with a high incidence of pneumothorax. ${ }^{3}$ Bonnano's catheter seems to avoid this problem and enables complete drainage. Our early subjective observation reveals that insertion of this catheter does not cause much pain to the patient during insertion. Therefore insertion of Bonnano's catheter can be safely performed by junior medical or surgical staff without the need for the extensive dissection that is inevitably required during standard thoracostomy.

The principle behind Bonanno's catheter insertion is similar to intravenous cannulation and therefore can be easily taught to junior physicians without the need for radiologic guidance. It offers reliable drainage of simple pleural effusion ${ }^{4}$ and provides a safe, less invasive, and more comfortable alternative to the standard tube thoracostomy. ${ }^{5}$ Importantly, removal of Bonanno's cath-

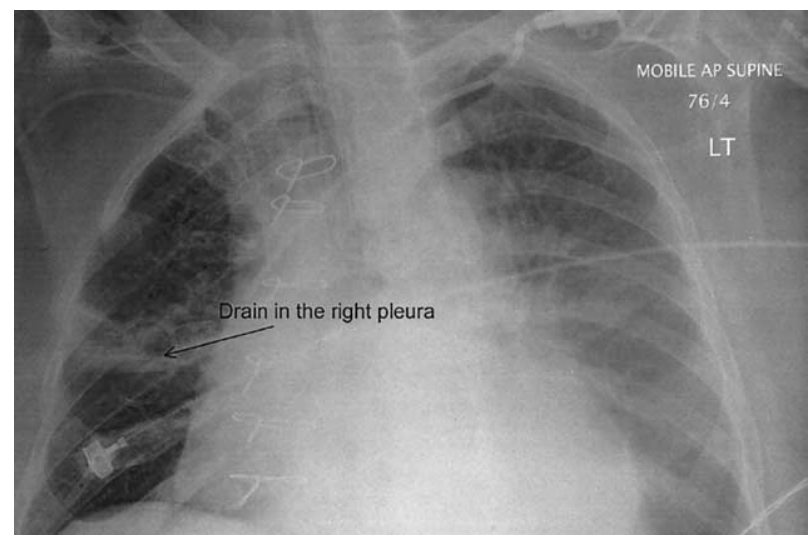

Figure 3. Chest x-ray film showing position.

eter does not require any purse-string sutures and therefore can be removed by a single nursing staff member without the need for additional assistance. We therefore recommend this novel technique. Prospective studies are warranted to compare its added benefits with those of conventional chest drains.

Special thanks to Mr Jeff Chandler, photographic medical illustrator for the Glenfield Hospital, Leicester, United Kingdom.

\section{References}

1. Bonanno PJ, Landers PE, Rock DE. Bladder drainage with the suprapubic catheter needle. Obstet Gynecol. 1970;35(5):807-12.

2. Carson MM, Barton DM, Morrison CC, Tribble CG. Managing pain during mediastinal chest tube removal. Heart Lung. 1994;23:500-5.

3. Mitri RK, Brown SD, Zurakowski D, Chung KY, Konez O, Burrows $\mathrm{PE}$, et al. Outcomes of primary image-guided drainage of parapneumonic effusions in children. Pediatrics. 2002;110(3):e37.

4. Grodzin CJ, Balk RA. Indwelling small pleural catheter needle thoracentesis in the management of large pleural effusions. Chest. 1997;111: 981-8.

5. Gammie JS, Banks MC, Fuhrman C, Pham SM, Griffith BP, Keenan RJ, et al. The pigtail catheter for pleural drainage: a less invasive alternative to tube thoracostomy. JSLS. 1999;3(1):57-61. 